\title{
Datation des restes humains découverts en milieu karstique en Centre-Ouest
}

\section{Bruno Boulestin}

\section{(2) OpenEdition \\ Journals}

Édition électronique

URL : http://journals.openedition.org/adlfi/1117

ISSN : 2114-0502

Éditeur

Ministère de la culture

Référence électronique

Bruno Boulestin, « Datation des restes humains découverts en milieu karstique en Centre-Ouest », ADLFI. Archéologie de la France - Informations [En ligne], Poitou-Charentes, mis en ligne le 01 mars 2008, consulté le 19 avril 2019. URL : http://journals.openedition.org/adlfi/1117

Ce document a été généré automatiquement le 19 avril 2019

(C) Ministère de la Culture et de la Communication, CNRS 


\title{
Datation des restes humains découverts en milieu karstique en Centre-Ouest
}

\author{
Bruno Boulestin
}

Identifiant de l'opération archéologique : 204639

Date de l'opération : 2008 (PC)

Dans les régions karstiques du Centre-Ouest, de nombreux restes humains ont été découverts dans des grottes, des avens ou des abris sous roche. Mais d'un site à un autre, ces restes sont très inégalement documentés. Une partie d'entre eux seulement sont en effet parfaitement attribués à des cultures ou des phases chronologiques par des contextes indiscutables. Il s'agit pour l'essentiel d'ossements humains qui proviennent de fouilles récentes, soit d'ensembles clos soit de sites stratifiés.

Pour beaucoup d'autres ensembles, au contraire, le contexte n'est que présumé, donc susceptible de discussion. C'est avant tout le cas de ceux, nombreux, qui ont été recueillis sans ou avec peu de méthode, soit dans le cadre de récoltes ou de fouilles anciennes, soit à l'occasion de trouvailles fortuites, en particulier par des spéléologues, soit encore lors de ramassages clandestins plus ou moins bien intentionnés.

Mais ces ensembles mal documentés n'ont pas l'apanage des problèmes d'attribution chronoculturelle. Pour une partie des assemblages osseux humains découverts en milieu karstique à l'occasion de fouilles modernes menées avec tout le soin nécessaire, cette attribution repose la plupart du temps sur l'association entre les restes humains et le mobilier archéologique mis au jour à leur proximité plus ou moins immédiate. Pour plausible qu'elle puisse paraître, cette association ne peut en réalité, sauf pour les ensembles clos indiscutables, que rarement être garantie absolument et sa fiabilité n'est donc généralement pas assurée. Ce problème se pose bien entendu en premier lieu dans les gisements où plusieurs occupations sont clairement attestées. On en prendra pour exemple la sépulture plurielle du Néolithique récent de la grotte des Perrats à Agris 
(Charente), attribuée avant datation directe au Bronze ancien sur la base des liaisons stratigraphiques telles qu'elles apparaissaient sur le terrain. Dans ce type de gisement, seules des datations absolues des ossements par le radiocarbone peuvent apporter des certitudes.

Plus, même dans des sites en apparence clos et homogènes, des " associations évidentes » peuvent parfois se révéler être des « liaisons dangereuses ». Ainsi, dans la grotte éponyme d'Artenac à Saint-Mary (Charente), l'apparente homogénéité de la sépulture collective, jusqu'à récemment considérée comme un ensemble clos du Néolithique final, a été complètement remise en cause par les analyses ${ }^{14} \mathrm{C}$, qui prouvent l'existence d'une occupation funéraire antérieure du Néolithique moyen, qui auparavant était insoupçonnable en l'absence de mobilier clairement attribuable à cette période. Et cet exemple ne saurait évidemment être tenu comme reflétant une situation exceptionnelle : les données régionales les plus récentes montrent en effet d'une part la fréquence apparente des sépultures du Néolithique moyen et récent en grotte, d'autre part la rareté du mobilier d'accompagnement dans ces sépultures, souvent réduit à quelques artefacts peu typiques.

Enfin, le problème des associations se présente également pour des assemblages osseux pour lesquels des datations absolues ont déjà été obtenues, mais indirectement, généralement à partir de charbons présumés de même époque. Dans ce cas, des distorsions peuvent être produites par l'utilisation de charbons intrusifs - les exemples sont légion -, ou de charbons bien contemporains des dépôts des restes humains, mais venant de bois déjà anciens (" effet vieux bois », avec risque de "vieillissement " des dates). Les discordances observées dans certains gisements entre le mobilier recueilli près des ossements et les résultats des datations absolues pourraient dans certains cas s'expliquer ainsi.

Les constatations précédentes ont conduit à proposer la mise en place d'un projet de recherche ayant pour but de dater directement, de façon absolue et aussi exhaustivement que possible, les restes humains découverts en milieu karstique en Centre-Ouest. Cette opération est désormais permise par la méthode moderne de datation AMS ( Accelerator Mass Spectrometer) sur os, plus précise et beaucoup moins destructrice que la méthode classique, et susceptible de dater directement des vestiges humains et de fournir ainsi des résultats indiscutables (réserve faite des limites liées à l'échantillon et à la méthode ellemême).

Ce programme de datation doit permettre :

1. De déterminer la position chronologique absolue des nombreux assemblages osseux dont la datation est indéterminée ou au mieux incertaine, qui constituent actuellement une documentation abondante, mais très peu exploitable.

2. De vérifier l'attribution chronologique de certains ensembles présumés bien datés et, éventuellement, de la rectifier.

3. D'affiner la datation de quelques ensembles indiscutables, mais pour lesquels on ne dispose que d'une date "large ", qu'il s'agisse d'une attribution exclusivement culturelle relative ( e. g., "Artenacien » ou "Bronze ancien ») ou d'une datation ${ }^{14} \mathrm{C}$ ancienne sur charbon assortie d'un intervalle de confiance après calibration supérieur à 400 ou 500 ans, excessif au regard des exigences actuelles. 
4. D'argumenter la discussion sur la durée de fonctionnement et la reconstitution des séquences d'intervention humaine dans des sites funéraires où les données du terrain indiquent plusieurs épisodes de dépôt des corps.

Au-delà de ces objectifs, ce projet est également l'occasion d'effectuer une recension la plus exhaustive possible des cavités du Centre-Ouest ayant livré des restes humains néolithiques ou protohistoriques. Ceci permettra dans un premier temps de vérifier, rectifier et mettre à jour, si nécessaire, la carte archéologique régionale, par ailleurs de réaliser une cartographie des occupations funéraires en grotte dans la région par époque et par culture.

Les analyses entreprises en 2008, lorsque leur résultat sera connu, permettront déjà de doubler le nombre de sites évalués et pratiquement celui des assemblages funéraires directement datés, les portant respectivement à 28 et 41 , pour un total de 61 dates. À terme, avec la poursuite du projet, ce seront environ 90 dates qui seront disponibles, concernant entre 40 et 50 sites et une soixantaine d'ensembles funéraires.

Nous disposerons alors d'une base solide pour poursuivre l'analyse de l'évolution des pratiques funéraires dans la région et la discussion de l'utilisation des grottes à des fins mortuaires, dans la continuité des programmes de recherche ou fouilles menés antérieurement ou en cours de réalisation, et pour orienter et fixer les priorités des recherches à venir en archéothanatologie dans la région.

BOULESTIN Bruno

\section{INDEX}

Index chronologique : Néolithique, Protohistoire

Thèmes : abri sous roche, AMS, carte archéologique, charbon de bois, chronologie, datation, grotte, inventaire, karst, mobilier, mobilier funéraire, occupation du sol, ossement humain, pratique funéraire, radiocarbone, sépulture, stratigraphie

operation Projet collectif de recherche (PCR)

Index géographique : Poitou-Charentes, Charente (16), Agris (16003)

\section{AUTEURS}

BRUNO BOULESTIN

BEN 